\title{
Correction of Radar QPE Errors for Nonuniform VPRs in Mesoscale Convective Systems Using TRMM Observations
}

\author{
YouCUN QI \\ Cooperative Institute for Mesoscale Meteorological Studies, University of Oklahoma, and NOAA/OAR/National Severe Storms \\ Laboratory, Norman, Oklahoma and Nanjing University of Information Science and Technology, Nanjing, China \\ JIAN ZHANG \\ NOAA/OAR/National Severe Storms Laboratory, Norman, Oklahoma \\ QING CAO \\ Advanced Radar Research Center, and Hydrometeorology and Remote Sensing Laboratory, University \\ of Oklahoma, Norman, Oklahoma \\ YANG HONG \\ Advanced Radar Research Center, and Hydrometeorology and Remote Sensing Laboratory, and School of Civil Engineering \\ and Environmental Sciences, University of Oklahoma, Norman, Oklahoma \\ XiAO-Ming Hu \\ Center for Analysis and Prediction of Storms, University of Oklahoma, Norman, Oklahoma
}

(Manuscript received 15 November 2012, in final form 13 May 2013)

\begin{abstract}
Mesoscale convective systems (MCSs) contain both regions of convective and stratiform precipitation, and a bright band $(\mathrm{BB})$ is often found in the stratiform region. Inflated reflectivity intensities in the BB often cause positive biases in radar quantitative precipitation estimation (QPE). A vertical profile of reflectivity (VPR) correction is necessary to reduce such biases. However, existing VPR correction methods for ground-based radars often perform poorly for MCSs owing to their coarse resolution and poor coverage in the vertical direction, especially at far ranges. Spaceborne radars such as the Tropical Rainfall Measuring Mission (TRMM) Precipitation Radar (PR), on the other hand, can provide high resolution VPRs. The current study explores a new approach of incorporating the TRMM VPRs into the VPR correction for the Weather Surveillance Radar-1988 Doppler (WSR-88D) radar QPE. High-resolution VPRs derived from the $\mathrm{K}_{\mathrm{u}}$-band TRMM PR data are converted into equivalent S-band VPRs using an empirical technique. The equivalent S-band TRMM VPRs are resampled according to the WSR-88D beam resolution, and the resampled (apparent) VPRs are then used to correct for BB effects in the WSR-88D QPE when the ground radar VPR cannot accurately capture the BB bottom. The new scheme was tested on six MCSs from different regions in the United States and it was shown to provide effective mitigation of the radar QPE errors due to BB contamination.
\end{abstract}

\section{Introduction}

Through the National Mosaic and Multi-Sensor Quantitative Precipitation Estimation (NMQ) system (Vasiloff

Corresponding author address: Youcun Qi, Cooperative Institute for Mesoscale Meteorological Studies, University of Oklahoma, and NOAA/OAR National Severe Storms Laboratory, 120 David L Boren Blvd., Norman, OK 73072.

E-mail: youcun.qi@noaa.gov; youcun.qi@gmail.com et al. 2007; Zhang et al. 2011; Seo et al. 2005), a real-time test bed for the research, development, and evaluation of national multisensor precipitation products, it was found that the ground-based radar quantitative precipitation estimations (QPEs) often suffer from overestimation errors in the trailing stratiform region of mesoscale convective systems (MCSs) (Houze 2004; Howard 2007). The overestimation was due to inflated reflectivities caused by melting snow/graupel (e.g., Ryde 1947; Wexler and Atlas 
1956; Fabry and Zawadzki 1995; Zhang and Qi 2010, hereafter ZQ10; Yang et al. 2013; Zhang et al. 2012; Qi et al. 2013a,b; Qi and Zhang 2013). MCSs account for a large portion of precipitation in both the central and eastern United States (Houze 2004; Howard 2007). Longlasting, slow moving MCSs are a major cause of flooding, which leads to large property and crop damages: interruptions of transportation; and, in the most extreme cases, injuries and deaths. Therefore, obtaining an accurate QPE for MCSs is very important.

MCSs consist of both convective and stratiform precipitation (Houze 2004; Howard 2007). A bright band (BB) is often found in the stratiform precipitation, and inflated reflectivity intensities in the $\mathrm{BB}$ region often cause positive biases in radar QPEs. A vertical profile of reflectivity (VPR) correction is necessary to reduce such biases (Koistinen 1991; Kitchen et al. 1994; ZQ10; Qi et al. 2013a,b; Qi and Zhang 2013). ZQ10 developed a real-time scheme for mitigating $\mathrm{BB}$ contamination in the Weather Surveillance Radar-1988 Doppler (WSR88D) radar QPEs for both cool season stratiform precipitation and warm season MCSs. In ZQ10, the vertical structure of the bright band was assumed to be horizontally uniform. Since height of the radar beam increases with increasing range, reflectivity variations along the range in a given tilt also represent the vertical variation of reflectivity. ZQ10 computed a range (height) profile of azimuthal mean reflectivity for each tilt, that is, the so-called apparent VPR (AVPR). Such a profile automatically adapts to the WSR-88D radar beam broadening effect with increasing range and simplifies the correction procedure (ZQ10). The word "apparent" signifies the beam broadening effects in the VPR. The BB bottom is identified from the AVPR by finding the first inflection point below the $\mathrm{BB}$ peak. The precipitation below the $\mathrm{BB}$ bottom is assumed to be invariant. Then all reflectivities within the $\mathrm{BB}$ layer, after being adjusted to its corresponding value at the $\mathrm{BB}$ bottom following the AVPR, can be used for surface precipitation estimation [Eq. (9) in ZQ10] without significant overestimation errors.

The effectiveness of the ZQ10 AVPR correction scheme is dependent on the accuracy of the BB bottom. The coolseason stratiform precipitation is usually widespread, and sufficient data samples can be collected near one or more radars for the AVPR calculations. The data near the radar contain observations at lower altitudes and have a better chance to capture the BB bottom in the AVPR than the data samples at far ranges. Stratiform precipitation regions in MCSs are usually smaller in area sizes than the coolseason stratiform precipitation systems, and the stratiform regions can sometimes be far away from any radars. The two factors combined can cause a problem when computing the ground radar AVPR, where few data points are available from lower altitudes. An accurate BB bottom is hard to find from the AVPR under such circumstances. Figure 1 shows one evolving MCS system that occurred on 27 May 2008 in Oklahoma and was observed by the WSR88D radar KTLX (Oklahoma City). The increasing height of the AVPR bottom with time (Figs. $1 a_{3}, b_{3}, c_{3}$ ) was a result of the MCS system moving away from the radar (Figs. $1 a_{1}, b_{1}, c_{1}$ ). As the MCS system moved away, there were fewer and fewer observations below the freezing level, as shown in the vertical cross sections (Figs. $1 \mathrm{a}_{2}, \mathrm{~b}_{2}$, $\mathrm{c}_{2}$ ). The sampling deficiency of the WSR-88D radar caused an artificial increase of the identified BB bottom with time in the ZQ10 scheme. This inaccurate BB bottom would cause insufficient corrections of overestimation errors in the radar QPE associated with the BB. Another challenge is the thicker BB depths in MCSs than those in the coolseason stratiform rain (Zhang et al. 2008; ZQ10; Zhang et al. 2012; Qi et al. 2013a,b; Qi and Zhang 2013). One of the main factors for the thicker BB depth was that the MCS $\mathrm{BB}$ area was less widespread than the cool-season stratiform $\mathrm{BB}$ and was often observed far away from the radar where the beam was wide. Other factors include a dry environment behind squall lines that can cause a slower melting process than in a moist environment and a descending rear-inflow jet that can accelerate the descent of the ice/snow and increase the vertical distance for the melting process to complete (McFarquhar et al. 2007; Ryzhkov et al. 2011). The thicker BB depth results in a lower and thinner layer of pure liquid in the vertical precipitation structure, which may not be observed by the ground radar, especially when the MCS is away from the radar. This issue often causes ineffective VPR corrections in the ZQ10 scheme.

To address the ground radar sampling limitations with respect to MCSs, the current study explores spaceborne radar observations of vertical precipitation structure, namely, the observations from the Tropical Rainfall Measuring Mission (TRMM) Precipitation Radar (PR). TRMM PR data has a vertical resolution of $250 \mathrm{~m}$, which is much higher than the WSR-88D radar resolution that varies from $1 \mathrm{~km}$ at a range of $\sim 60 \mathrm{~km}$ to $5 \mathrm{~km}$ at $300 \mathrm{~km}$ given the WSR-88D scanning strategies (Zhang et al. 2005). The lowest TRMM observation can reach $250 \mathrm{~m}$ above ground level (AGL), which would provide better coverage of lower altitudes than WSR-88D radars beyond a range of $60 \mathrm{~km}$ (Zhang et al. 2005). Cao et al. (2013a) explored the usage of TRMM VPRs in the WSR-88D radar QPEs for cool-season stratiform precipitation. The current study proposes a VPR correction scheme using a combination of WSR-88D and TRMM PR VPRs for the brightband areas in MCSs. Specifically, the WSR-88D VPRs are used when they can accurately capture the BB bottom, and TRMM PR VPRs are used otherwise. 

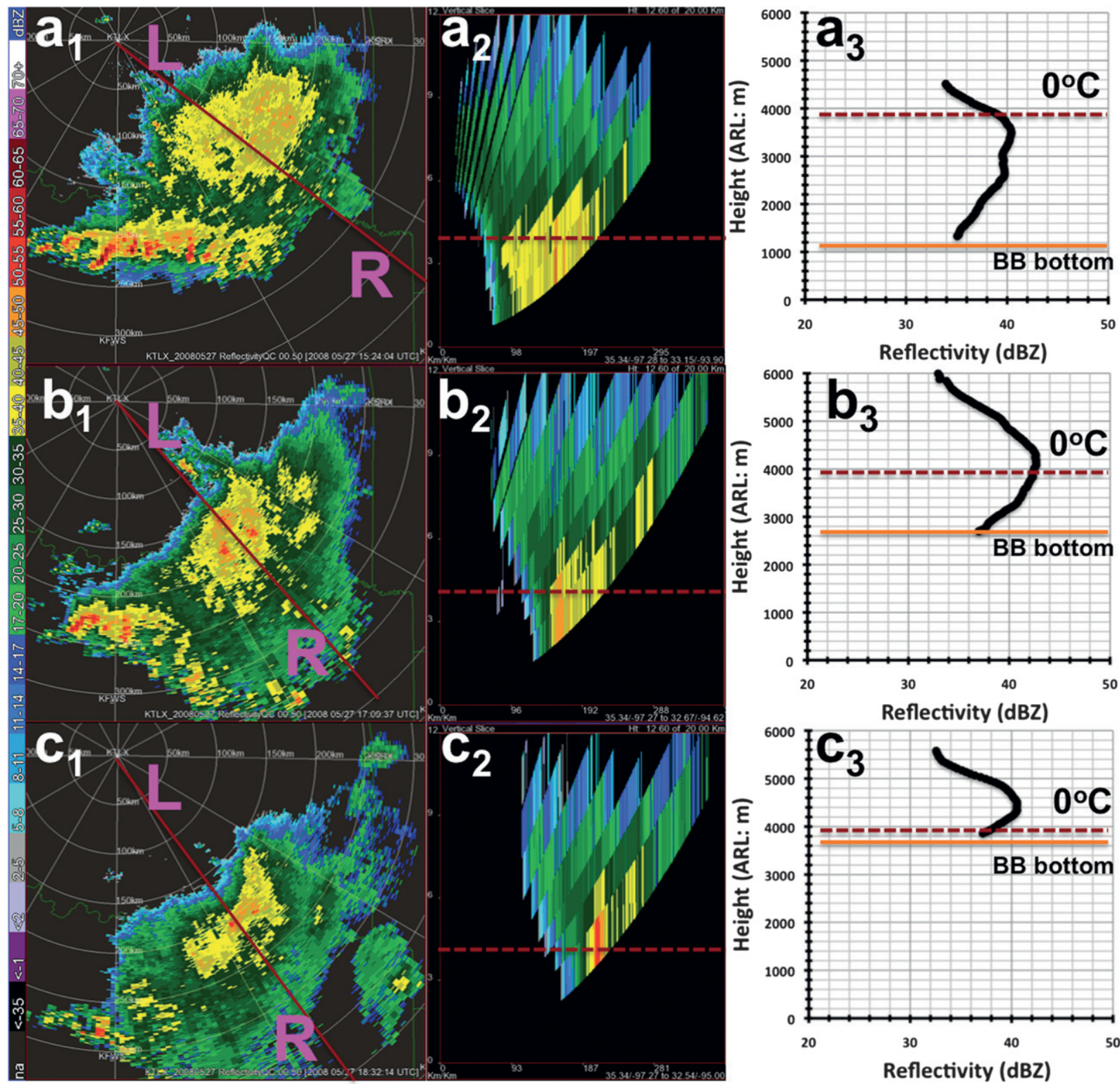

FIG. 1. KTLX radar at (a) 1524 UTC, (b) 1709 UTC, and (c) 1832 UTC 27 May 2008: (left) base reflectivity on $0.50^{\circ}$ tilt, (middle) vertical cross sections along the brown lines in the left column, and (right) apparent vertical profile of reflectivity (AVPR) derived from brightband area with ZQ10. The purple letters " $L$ " and " $R$ " in the left column indicate the left and right ends of the cross sections in the middle column. The brown dashed lines in the middle and right columns represent the $0^{\circ} \mathrm{C}$ height level at the radar site, and the orange solid lines in the right column represent the BB bottoms derived from AVPR with ZQ10.

TRMM PR is in the $\mathrm{K}_{\mathrm{u}}$ band $(13.8 \mathrm{GHz})$ and the WSR$88 \mathrm{Ds}$ are in the $\mathrm{S}$ band $(2.8 \mathrm{GHz})$, so a conversion of the $\mathrm{K}_{\mathrm{u}^{-}}$ band VPRs to their S-band equivalent is necessary. An empirical model for such conversion (Cao et al. 2013b) is introduced in section 2 along with the description of how the TRMM PR VPRs are applied for the correction of groundradar QPE; section 3 presents several case study results of the new VPR correction. The last section provides a summary of the current study and an outlook for future work.

\section{Methodology}

The new ground and spaceborne radar VPR correction scheme has two major components: one is the ZQ10 scheme and the other is the new TRMM VPR correction. The ZQ10 scheme is applied when the bottom level of the WSR-88D AVPR is close to the surface [i.e., lower than $1 \mathrm{~km}$ above the radar level (ARL)], and a new TRMM VPR correction is applied otherwise. The $1 \mathrm{~km}$ 
ARL criterion was chosen based on real-time radar QPEs in the NMQ system (Zhang et al. 2011). Comparisons of the radar quantitative precipitation estimation (QPE) with rain gauge observations indicated that the ZQ10 scheme produced reasonably accurate rainfall estimates whenever the AVPR contained sufficient data samples at and below $1 \mathrm{~km}$ ARL. When there was little data data below $1 \mathrm{~km}$ ARL, the ZQ10 scheme appeared to be insufficient in correcting for the BB-induced biases in the radar QPE, so the higher the bottom of the AVPR, the less the AVPR correction accuracy.

The ZQ10 VPR correction consists of the following five steps:

1) segregate convective and stratiform precipitation on each WSR-88D tilt based on the vertically integrated liquid amounts (ZQ10) and then delineate BB areas inside the stratiform precipitation based on composite reflectivities;

2) compute an apparent VPR (blue line in Fig. 2) in a given tilt by averaging reflectivities $\left(\mathrm{mm}^{6} \mathrm{~m}^{-3}\right)$ in azimuthal direction in the $\mathrm{BB}$ area and then convert into the log scale ( $\mathrm{dBZ})$;

3) find the BB peak in the AVPR by searching the maximum reflectivity within $\pm 1 \mathrm{~km}$ of the atmospheric $0^{\circ} \mathrm{C}$-level height and then find the $\mathrm{BB}$ top (bottom) by searching the first inflection point above (below) the BB peak in the AVPR;

4) derive a parameterized, two-piece linear AVPR (one between BB top and peak and another between BB peak and bottom) through a least squares fitting;

5) adjust reflectivities in the $\mathrm{BB}$ area to the corresponding values at the $\mathrm{BB}$ bottom following the parameterized linear AVPR.

Figure 2 illustrates the concept of the ZQ10 scheme, and more details can be found in ZQ10.

The TRMM VPR correction consists of the following three steps for any given MCS event: 1) convert TRMM PR VPRs in the BB area of the MCS from $K_{u}$ to $S$ band for each TRMM pixels, 2) compute an event mean reference VPR from the converted S-band TRMM VPRs for the MCS event, and 3) compute an instantaneous reference TRMM VPR for any given WSR-88D volume scan by adjusting the event mean reference VPR to the appropriate freezing level height and then apply the VPR correction to reflectivities in the $\mathrm{BB}$ area for the volume scan. The TRMM VPR steps are presented in detail below.

\section{a. $K_{u}$-band to $S$-band conversion}

Since the TRMM PR operates at a much higher frequency $\left(\mathrm{K}_{\mathrm{u}}\right.$ band, $\left.13.8 \mathrm{GHz}\right)$ than S-band WSR-88D radars, it is more sensitive to Mie scattering of hydrometeors,

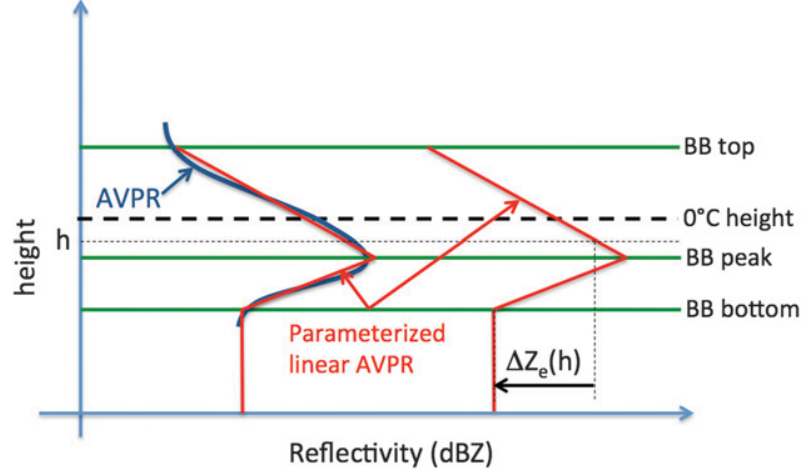

FIG. 2. The conceptual model of ZQ10 scheme. The blue curve represents an AVPR computed by averaging in the azimuthal direction WSR-88D radar observed reflectivities in the $\mathrm{BB}$ area on a given tilt. BB peak (middle green line) is defined as the height of the maximum reflectivity within $\pm 1 \mathrm{~km}$ of the atmospheric $0^{\circ} \mathrm{C}$ height (black dashed line). BB top and bottom (top and bottom green lines, respectively) are then found by searching for the first inflection points above and below the BB peak, respectively. The red lines represent the parameterized linear AVPR obtained by fitting two lines to the AVPR, one above and the other below the $\mathrm{BB}$ peak, while the reflectivity below the BB bottom is assumed invariant. The amount of correction, $\Delta Z_{e}(h)(\mathrm{dB} Z)$, applied to any reflectivities observed at the height of $h$ in the $\mathrm{BB}$ area is the difference between the reflectivities at $h$ and at the bottom in the parameterized AVPR. More details can be found in the text.

while the latter is more sensitive to Rayleigh scattering. The different scattering characteristics of the two frequencies cause different VPR measurements by TRMM PR and WSR-88D radar. Therefore, the utilization of TRMM PR measurements to correct the S-band radar QPE requires a conversion of the $\mathrm{K}_{\mathrm{u}}$-band VPRs to the S-band ones.

The vertical profile of reflectivity (VPR) conversion in this study follows the empirical approach introduced in Cao et al. (2013b). The vertical profile of stratiform precipitation is typically divided into three layers, that is, ice, melting snow, and rain layers from the storm top to the surface. Cao et al. derived several empirical polynomial relations addressing different phases (solid, liquid, or mixing) of hydrometers (raindrop, ice particle, and snowflake) in the precipitating cloud and for different particle size distributions. Since the exact hydrometeor species and melting rates in the melting layer of the MCS trailing stratiform region are not known at any given time with the existing observational systems, a simple model was adopted for the $\mathrm{K}_{\mathrm{u}}$-band to S-band VPR conversion. The simple model assumes a microphysical process that goes from dry snow to melting snow and to rain in the three layers of above, within, and below the melting layer, respectively. Further the melting rate (i.e., the increasing rate of the hydrometeor mass changed from the solid to liquid phase) was assumed to be linear with decreasing 
TABLE 1 . Summary of the events.

\begin{tabular}{|c|c|c|c|c|}
\hline Event & Radar & $\begin{array}{l}\text { Number of } \\
\text { R-G pairs }\end{array}$ & Time and date & Event summary \\
\hline 1 & $\operatorname{KTLX}\left(35.3^{\circ} 3 \mathrm{~N}, 97.27^{\circ} \mathrm{W}\right)$ & 67 & 0600-1400 UTC 13 May 2005 & One TRMM PR pass \\
\hline \multirow[t]{2}{*}{2} & $\operatorname{KTLX}\left(35.33^{\circ} \mathrm{N}, 97.27^{\circ} \mathrm{W}\right)$ & 112 & 1000-2300 UTC 24 May 2007 & Two TRMM PR passes \\
\hline & $\mathrm{KVNX}\left(36.74^{\circ} \mathrm{N}, 98.13^{\circ} \mathrm{W}\right)$ & 168 & & \\
\hline \multirow[t]{2}{*}{3} & KFWS $\left(32.57^{\circ} \mathrm{N}, 97.30^{\circ} \mathrm{W}\right)$ & 29 & 1200-2000 UTC 27 May 2008 & One TRMM PR pass \\
\hline & $\operatorname{KTLX}\left(35.33^{\circ} \mathrm{N}, 97.27^{\circ} \mathrm{W}\right)$ & 56 & & \\
\hline \multirow[t]{2}{*}{4} & KFDR $\left(34.36^{\circ} \mathrm{N}, 98.97^{\circ} \mathrm{W}\right)$ & 152 & 1200 UTC 14 May to 0400 UTC 15 May 2010 & Two TRMM PR passes \\
\hline & KFWS $\left(32.57^{\circ} \mathrm{N}, 97.30^{\circ} \mathrm{W}\right)$ & 136 & & \\
\hline \multirow[t]{4}{*}{5} & $\operatorname{KBMX}\left(33.17^{\circ} \mathrm{N}, 86.77^{\circ} \mathrm{W}\right)$ & 257 & 0000 UTC 9 Mar to 0600 UTC 10 Mar 2011 & Two TRMM PR passes \\
\hline & $\operatorname{KGWX}\left(33.90^{\circ} \mathrm{N}, 88.33^{\circ} \mathrm{W}\right)$ & 227 & & \\
\hline & $\mathrm{KFFC}\left(33.36^{\circ} \mathrm{N}, 84.57^{\circ} \mathrm{W}\right)$ & 172 & & \\
\hline & $\operatorname{KEVX}\left(30.57^{\circ} \mathrm{N}, 85.92^{\circ} \mathrm{W}\right)$ & 188 & & \\
\hline \multirow[t]{2}{*}{6} & $\mathrm{KFFC}\left(33.36^{\circ} \mathrm{N}, 84.57^{\circ} \mathrm{W}\right)$ & 149 & 0200-1300 UTC 5 Apr 2011 & Two TRMM PR passes \\
\hline & $\mathrm{KJGX}\left(32.67^{\circ} \mathrm{N}, 83.35^{\circ} \mathrm{W}\right)$ & 118 & & \\
\hline Total & $13^{*}$ radars & 1831 & $233 \mathrm{~h}$ & Six events \\
\hline
\end{tabular}

* Some radars are counted more than once because they appeared in multiple events.

height. Cao et al. (2013b) had applied the simple $\mathrm{K}_{\mathrm{u}}$-band to S-band VPR conversion model to TRMM PR data and cross-validated with the ground radar observations and demonstrated that the model was able to capture the main vertical reflectivity structure of the melting layer.

As mentioned earlier, the $\mathrm{K}_{\mathrm{u}}$-band to S-band VPR conversion requires knowledge of the brightband top, peak, and bottom heights. The top (bottom) of the melting layer is determined by finding the first reflection point above (below) the BB peak in the TRMM VPR, and the BB peak was defined as the maximum reflectivity point within $1500 \mathrm{~m}$ below the background $0^{\circ} \mathrm{C}$ height. Cao et al. (2013b) studied sensitivities of the $\mathrm{K}_{\mathrm{u}}$-band to S-band VPR conversion to different hydrometeor types, densities, and sizes. The sensitivity study indicated that the dual-frequency ratios for small ice particles and different densities of small snow aggregates are not substantially different. For instance, for pure snow aggregates and pure graupel of 4-mm diameter size at the same $\mathrm{K}_{\mathrm{u}}$-band reflectivity, the corresponding S-band reflectivity is $\sim 4 \mathrm{~dB}$ different. Since a BB peak reflectivity is usually $8-10 \mathrm{~dB}$ stronger than the corresponding reflectivity at the bottom of the bright band (Fabry and Zawadzki 1995), the simple VPR conversion model should still capture the main vertical structure of the BB in the MCSs and provide mitigation to the large overestimation biases in the radar quantitative precipitation estimation.

\section{b. Reference $V P R$}

The TRMM products used in the current study were generated by the latest PR qualitative algorithm (2A23) (Awaka et al. 1998, 2007) and PR profile algorithm (2A25) (Meneghini et al. 2000, 2004; Iguchi et al. 2000, 2009). The $2 \mathrm{~A} 23$ products provide the precipitation type classification and heights associated with the melting layer, and the $2 \mathrm{~A} 25$ products include the vertical profiles of attenuation-corrected (Iguchi et al. 2000) radar reflectivity.

Six MCS events (Table 1) with strong BB and overlapping ground radar and TRMM PR observations were analyzed in this study. There were $233 \mathrm{~h}$ of WSR-88D radar data with an update interval of $\sim 5 \mathrm{~min}$. TRMM has a much lower data update rate, which is about $91.5 \mathrm{~min}$ per orbit. There were only one or two passes of TRMM data available for each of the six MCS events. Given the strong vertical gradients of reflectivities around the melting layer and relative uniformity and persistency of stratiform precipitation, the horizontal and temporal variations of reflectivity are considered to be much smaller than the vertical variation. Further, Zhang et al. (2008) studied seven months of more than 130 WSR-88D radar data in the continental U.S. domain and found that the relative heights of BB top, peak, and bottom varied little with season and latitudes. Based on these observations, the current study assumes that the vertical structure within the melting layer remains unchanged during an event whenever the $\mathrm{BB}$ is apparent from ground radar observations, while the height of the melting layer may change with time. For each MCS event, a mean reference VPR was derived from all the TRMM observations in the $\mathrm{BB}$ area of stratiform precipitation, and it was considered to represent the vertical BB structure throughout the event.

The procedure for deriving the event mean reference VPRs from TRMM PR observations is briefly as follows. First, the stratiform precipitation area is determined according to the precipitation type classification in $2 \mathrm{~A} 23$ products, and within the stratiform precipitation $\mathrm{BB}$ 

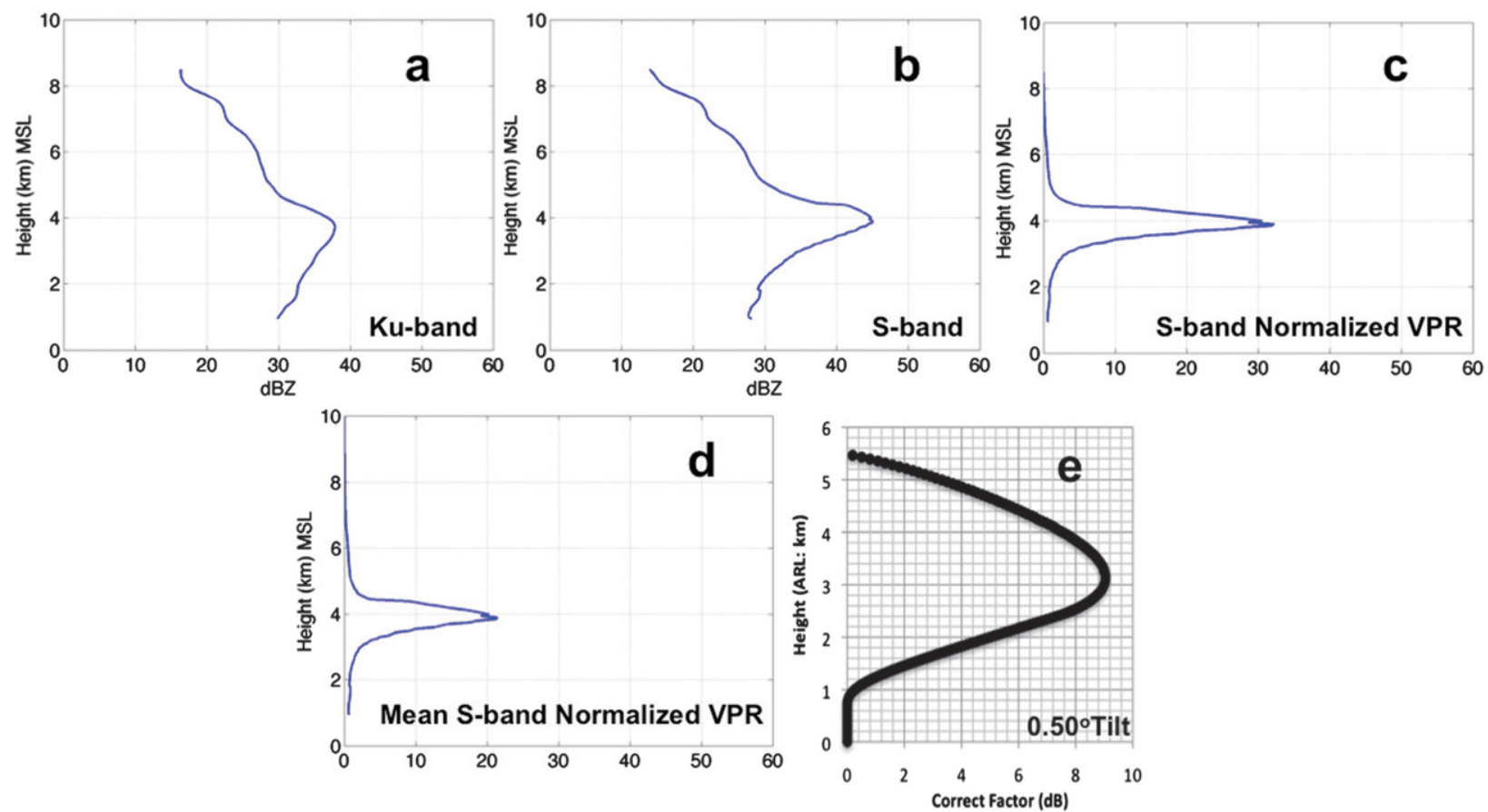

FIG. 3. (a) $\mathrm{K}_{\mathrm{u}}$-band vertical profile of reflectivity (VPR) from one TRMM PR pixel at 1900 UTC 27 May 2008 and (b) S-band VPR converted from (a) using empirical relations derived in the three regions (Cao et al. 2013b). (c) Normalized S-band VPR from (b). (d) Mean normalized S-band VPR calculated from all identified stratiform rainfall; see details in the text. (e) Reflectivity correction factor on the $0.50^{\circ}$ tilt.

areas are delineated wherever the composite reflectivity from the ground radar is greater than $30 \mathrm{dBZ}$ (ZQ10). Second, individual TRMM PR VPRs (e.g., Fig. 3a) for each pixel in the BB area are converted into S-band VPRs (e.g., Fig. 3b) using the empirical approach mentioned in section $2 \mathrm{a}$. Third, each converted S-band TRMM VPR is normalized (Fig. 3c) by dividing all reflectivity values in the S-band VPR by the reflectivity at a reference height, which was defined as the third point above the lowest valid level in the TRMM VPR at any given pixel. The reference point was chosen to correct the reflectivities observed at higher altitudes (specifically in the BB) to a level as close to the ground as possible such that an accurate QPE can be obtained. Meanwhile, the reference point needs to be a few hundred meters above the ground to avoid potential contaminations from topography and surface objects. Finally, the individual normalized S-band TRMM VPRs (Fig. 3c) are averaged over all of the pixels within the event to obtain the final mean reference S-band VPR (Fig. 3d).

\section{c. VPR correction}

TRMM VPRs are applied in the VPR correction for WSR-88D volume scans when the bottom of the WSR-88D AVPR is higher than $1 \mathrm{~km}$ ARL. For each of those volume scans, an instantaneous reference VPR was derived by adjusting the TRMM event mean reference VPR vertically such that the BB top in the mean VPR matched the freezing level height at the time of the volume scan. Then the VPR corrected reflectivity, $\hat{Z}_{e}\left(h_{0}\right)$ $(\mathrm{dBZ})$, is obtained by

$$
\hat{Z}_{e}\left(h_{0}\right)=Z_{e}^{\mathrm{obs}}(h)-\Delta Z_{e}
$$

and

$$
\Delta Z_{e}=10 \log _{10}\left[\int_{x=h-\Delta h}^{x=h+\Delta h} \rho(x) f^{4}(x) d x\right]
$$

where $h_{0}$ is the reference height to which the reflectivities of the BB area are adjusted and $Z_{e}^{\text {obs }}(h)$ is the WSR-88D reflectivity observed at height $h$ (i.e., the center of the radar bin). In Eq (2) $\Delta Z_{e}(\mathrm{~dB})$ is the reflectivity correction factor (e.g., Fig. 3e), $\Delta h$ is the halfwidth of radar beam, $f^{4}(x)$ is the two-way radar antenna gain function, and $\rho(x)$ is the normalized instantaneous reference TRMM VPR (i.e., the curve in Fig. 3d, but with the vertical freezing level height adjustment).

When the bottom of the WSR-88D apparent VPR (AVPR) is lower than or equal to $1 \mathrm{~km}$ ARL, the 


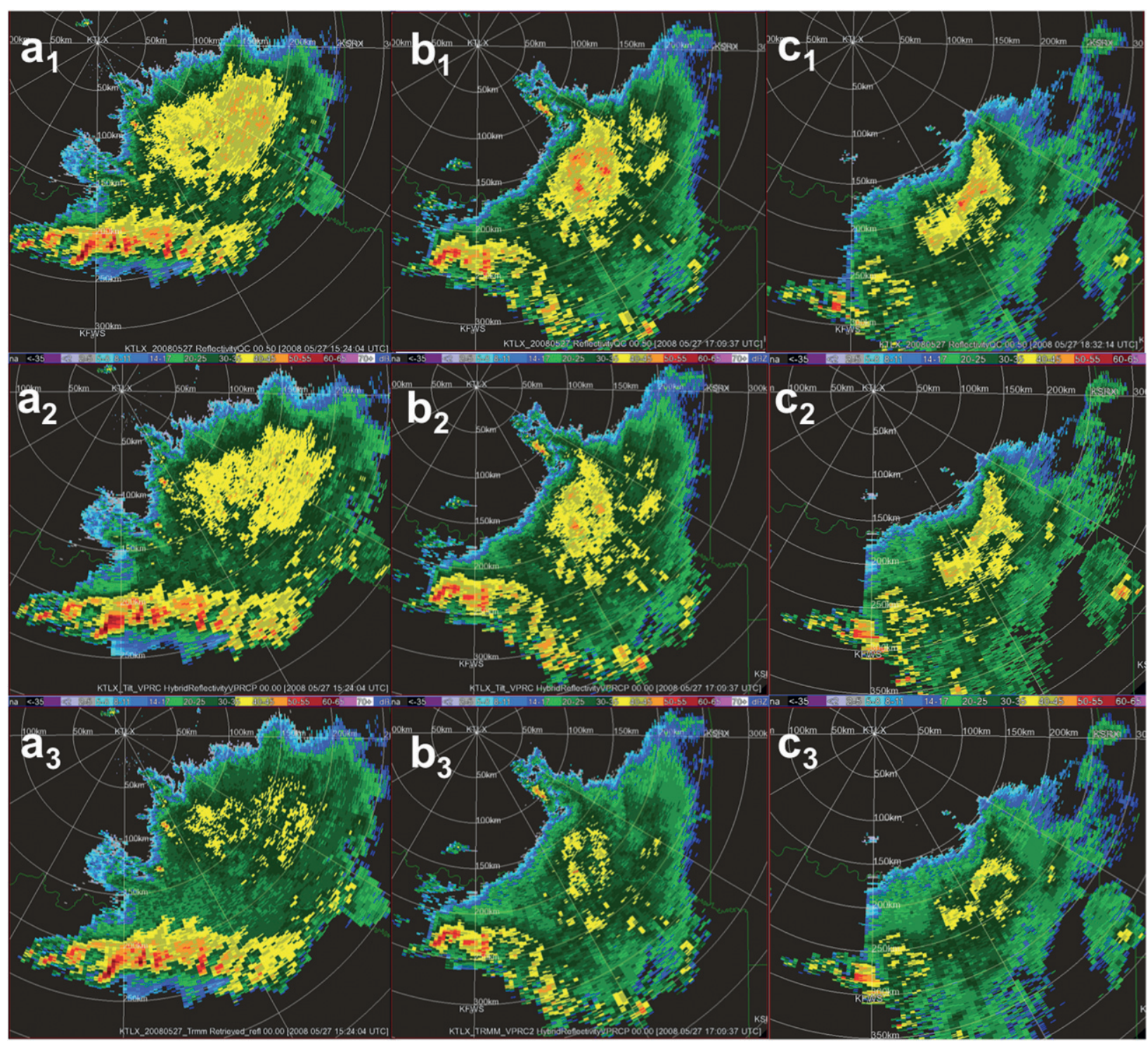

FIG. 4. As in Fig. 1 but of reflectivity on $0.50^{\circ}$ tilt (top) before VPR correction, (middle) after VPR correction with ZQ10, and (bottom) after VPR correction with New.

reflectivity correction factor is computed from the WSR-88D parameterized linear AVPR (ZQ10) as

$$
\Delta Z_{e}(h)=Z_{e}^{a}(h)-Z_{e}^{a}\left(h_{0}\right)
$$

Here $Z_{e}^{a}(h)$ and $Z_{e}^{a}\left(h_{0}\right)$ are the reflectivity values (dBZ) in the WSR-88D parameterized linear AVPR at the heights of $h$ and $h_{0}$ (i.e., the BB bottom in Fig. 2), respectively. Note that all WSR-88D radar beam height computations in the current study follow the $4 / 3$ earth radius model in Doviak and Zrnić (1993).

Figure 4 shows three examples of the WSR-88D reflectivity fields before (Figs. $4 \mathrm{a}_{1}, \mathrm{~b}_{1}, \mathrm{c}_{1}$ ) and after VPR corrections based on the ground-radar-only scheme
(ZQ10) (Figs. $4 a_{2}, b_{2}, c_{2}$ ) and based on the new ground and spaceborne radar scheme (ZQ10 + TRMM PR, hereafter called New) (Figs. $4 a_{3}, b_{3}, c_{3}$ ). Comparing Fig. $4 a_{1}$ with Fig. $4 a_{2}$, the high-reflectivity region behind the squall line was mitigated with ZQ10 correction, but significant high intensity echoes remained in the $\mathrm{BB}$ area (Fig. $4 a_{2}$ ). The reflectivity field after the New VPR correction, on the other hand, showed a much more uniform distribution in the trailing stratiform precipitation (Fig. $4 \mathrm{a}_{3}$ ) than did the ZQ10 corrected reflectivity (Fig. $4 \mathrm{a}_{2}$ ), with little BB contamination remaining. The different VPR correction results were explained by the differences between the WSR-88D AVPR (Fig. 1 $\mathrm{c}_{1}$ ) and the TRMM AVPR (Fig. 3e), where the former indicated 

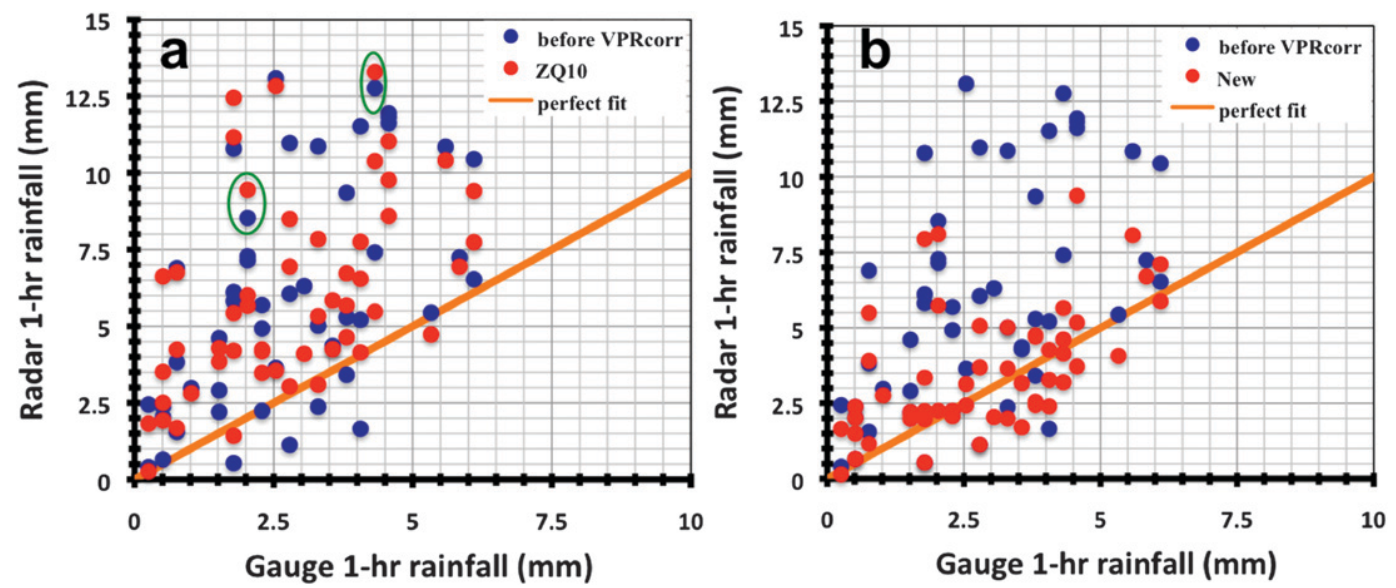

FIG. 5. Scatterplots of 1-h radar precipitation estimates before (blue dots) and after (red dots) the VPR correction for (a) ZQ10 and (b) New vs gauge observations. The data are from KTLX 1200-2000 UTC 27 May 2008.

a 1.4-km (ARL) BB bottom and a 5-6-dB reflectivity correction factor between the BB peak and the bottom, while the latter showed a $0.8-\mathrm{km}$ (ARL) BB bottom and a $9-\mathrm{dB}$ correction factor. Similarly, at 1709 and 1832 UTC 27 May 2008, the WSR-88D AVPR failed to provide an accurate estimate of the BB bottom because the storm moved far away from the radar (Figs. $1 a_{2}, a_{3}$ ), and there were no data available below 2.6 and $3.8 \mathrm{~km}$ ARL (Figs. 1 $c_{2}, c_{3}$ ), respectively. The vertical cross sections in Figs. $1 b_{2}, b_{3}$ demonstrate the sampling deficiency of the WSR-88D radar at lower altitudes as the range increases. As a result, the ZQ10 VPR-corrected reflectivity field still contained significant contamination from the bright band (Figs. $4 b_{2}, c_{2}$ ), and the derived QPE still had large overestimation errors (Fig. 5a). After the TRMM VPR correction, the BB contamination is remarkably reduced (Figs. $4 \mathrm{~b}_{3}, \mathrm{c}_{3}$ ) and the derived QPE had little overestimation (Fig. 5b). Figure 4 also showed that the trailing stratiform precipitation was not perfectly persistent and some temporal variations existed. However, compared to the large vertical variations of reflectivity around the melting layer (Fig. 3e), such variations, especially in the BB areas, are relatively small. Therefore, a VPR correction based on the mean TRMM VPR should still have positive impacts in reducing the radar QPE errors associated with the BB. More case study results, shown in the next section, confirmed such impacts.

The new VPR correction is evaluated quantitatively through comparisons of the radar-derived QPEs with the surface rain gauge observations. Figure 5 shows hourly radar rainfall estimates before and after the VPR corrections compared against gauge observations for the event shown in Figs. 1 and 4. The comparison was for BB areas only where the VPR correction was applied. Since $\mathrm{BB}$ areas are in the stratiform precipitation, the Marshall et al. (1955) $Z-R$ relationship of $Z=200 R^{1.6}$ was used when converting the radar reflectivities into rain rates. The same $Z-R$ relationship is also used in the NMQ system for stratiform precipitation (Zhang et al. 2011). The rain rates were then aggregated into hourly accumulations and compared with hourly gauge observations. The ZQ10 scheme provided little mitigation for the radar QPE overestimation (Fig. 5a) owing to the radar sampling issues discussed above. There were even a few points (marked by green circles in Fig. 5a) where the overestimation error slightly increased after the VPR correction. The points were from the top part of the BB layer (e.g., at 5-5.5 km ARL in Figs. $1 c_{2}, c_{3}$ ). Owing to incomplete depictions of the lower half of the BB layer in the WSR-88D AVPRs, the VPR correction adjusted the reflectivities to the bottom of the AVPR (i.e., 2.6 and $3.8 \mathrm{~km}$ ARL in Figs. $1 c_{2}, c_{3}$, respectively), which resulted in a net increase in the reflectivity values. The hourly radar QPEs after the new VPR correction agreed much better with the gauge observations (Fig. 5b) and removed the overestimation biases at most of the points.

\section{Case study}

A more extensive evaluation of ZQ10 and New VPR correction schemes was performed using six MCS precipitation events from different regions in the United States (Table 1). The data for the six events included 1831 hourly Hydrometeorological Automated Data System (HADS) (http://www.nws.noaa.gov/oh/hads) gauges and $233 \mathrm{~h}$ of volume scan data from 13 WSR-88D radars. Figure 6 shows a comparison of hourly radar rainfall estimates before and after the VPR corrections (ZQ10 and New) with the HADS observations for six MCS events. Three scores are calculated to assess the performance of the two VPR correction 


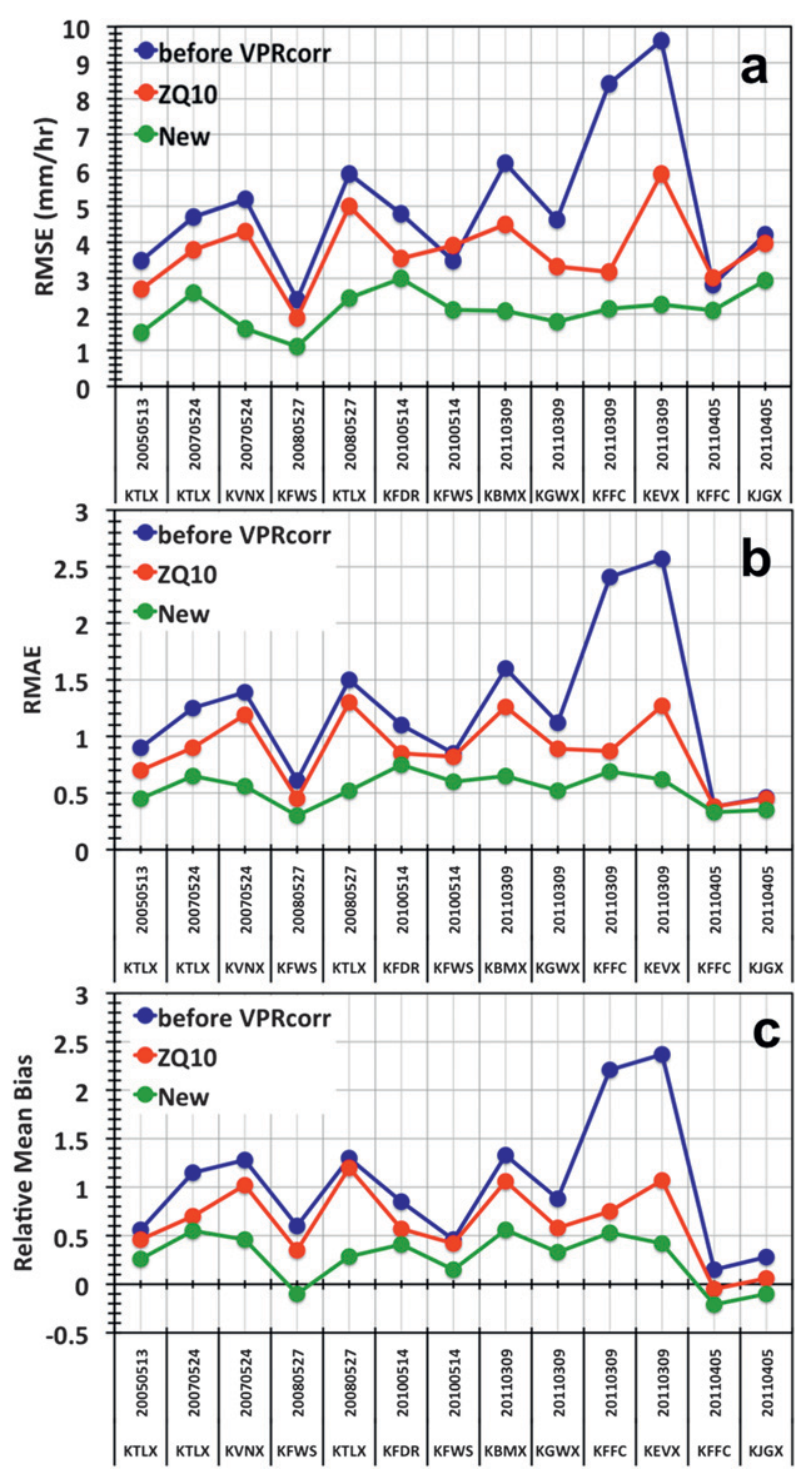

FIG. 6. The (a) RMSE, (b) RMAE, and (c) relative mean bias scores for radar precipitation estimates before (blue) and after the ZQ10 (red) and the New (green) AVPR corrections.

methods: 1) the radar-gauge rms error, RMSE = $\left.\left\langle\left|A_{R}-A_{G}\right|^{2}\right\rangle^{1 / 2} ; 2\right)$ the relative mean absolute error, $\mathrm{RMAE}=\left|\left\langle A_{R}\right\rangle-\left\langle\mathrm{A}_{\mathrm{G}}\right\rangle\right| /\left\langle A_{G}\right\rangle$; and 3) the relative mean bias, RMB $=\left\langle A_{R}-\mathrm{A}_{\mathrm{G}}\right\rangle /\left\langle A_{G}\right\rangle$, where $A_{R}$ and $A_{G}$ represent radar and gauge 1-h rainfall, respectively, for any given radar-gauge $(\mathrm{R}-\mathrm{G})$ pair and the angle brackets indicate averaging over all such pairs. A positive (negative) relative mean bias indicates that the radar has overestimated (underestimated) the rainfall assuming the gauge measures are the ground "truth." In this study, a valid $\mathrm{R}-\mathrm{G}$ pair is defined as a pair in which the gaugemeasured hourly rainfall is $0.8 \mathrm{~mm}$ or more. Other gauge data with less hourly rainfall amounts were omitted in order to reduce the errors caused by the minimum precipitation threshold of the rain gauge (e.g., Klazura et al. 1999; Anagnostou and Krajewski 1999).

As Fig. 6 shows, both New and ZQ10 approaches improved the original radar rainfall estimation, which was degraded by BB contamination. The New method provided further improvement upon ZQ10 in reducing the RMSE and RMAE for all the events (Figs. 6a,b). The most significant improvements are for KNVX20070524, KTLX20080527, KFWS20100514, KBMX20110309, and KEVX20110309, where the TRMM VPR correction provided $\sim 50 \%$ more reduction of the overestimation errors over ZQ10. These results showed a great potential of the spaceborne and ground radar combined VPR correction approach in providing a high-quality fineresolution precipitation product for improved meteorological and hydrological predictions.

\section{Summary and future work}

This study explores a "New" approach where spaceborne radar (TRMM PR) observations are integrated into the vertical profile of reflectivity correction of the ground radar quantitative precipitation estimation (QPE) in trailing stratiform rain areas of mesoscale convective systems. First, high-resolution vertical profile of reflectivity (VPR) derived from TRMM PR observations, which were in $\mathrm{K}_{\mathrm{u}}$-band, were converted into S-band VPRs using an empirical approach introduced in Cao et al. (2013b). The converted TRMM VPRs are then resampled according to the WSR-88D radar beam geometry and applied in the correction of the WSR-88D reflectivity field to remove contaminations of a bright band. The New VPR correction was tested with six MCS precipitation events chosen from different geographical regions in the central and eastern United States. Compared to the original ZQ10, the New method provided more effective mitigation of $\mathrm{BB}$ contaminations in the WSR-88D radar QPE as the TRMM PR observations provided higher resolution and a more complete depiction of the vertical structure of the BB layer than did the ground based radar.

The new algorithm has a limitation in that only one or two passes of TRMM are available for each MCS event, so only one reference TRMM VPR was computed and then applied for each event. The reference VPR cannot capture spatial and temporal variations of the vertical precipitation structure. However, such variations are much smaller than the vertical variation of reflectivity in strong BB areas where the ground radar QPE has the most noticeable biases. The reference TRMM VPR was able to capture the main vertical structure of the BB layer and to mitigate the large-scale overestimation errors in the WSR-88D radar QPE associated with the bright 
band. The case studies presented in section 3 clearly demonstrated such positive impacts of the TRMM VPRs.

The current method was designed for correcting the overestimation bias in ground radar QPEs caused by strong BBs in the trailing stratiform rain of mesoscale convective systems. It is also applicable to cool-season stratiform rain where ground radar has a poor coverage (e.g., the western United States). The launch of the Global Precipitation Mission satellite network can provide more frequent spaceborne radar observations and increase the usefulness of the current method in operations.

Acknowledgments. Major funding for this research was provided under NOAA-University of Oklahoma Cooperative Agreement NA17RJ1227. This manuscript has greatly benefited from the comments of anonymous reviewers.

\section{REFERENCES}

Anagnostou, E. N., and W. F. Krajewski, 1999: Real-time radar rainfall estimation. Part II: Case study. J. Atmos. Oceanic Technol., 16, 198-205.

Awaka, J., T. Iguchi, and K. Okamoto, 1998: Early results on rain type classification by the Tropical Rainfall Measuring Mission (TRMM) Precipitation radar. Proc. Eighth URSI Commission F Open Symp., Averio, Portugal, URSI, 143-146.

$\longrightarrow,-$, and,- 2007 : Rain type classification algorithm. Measuring Precipitation from Space: EURAINSAT and the Future, V. Levizzani, P. Bauer, and F. J. Turk, Eds., Springer, 213-224.

Cao, Q., Y. Hong, J. J. Gourley, Y. Qi, J. Zhang, Y. Wen, and P. Kirstetter, 2013a: Statistical and physical analysis of vertical structure of precipitation in mountainous west region of the United States using 11+ years of spaceborne observations from TRMM Precipitation Radar. J. Appl. Meteor. Climatol., 52, 408-424.

- - , Y. Qi, Y. Wen, J. Zhang, J. J. Gourley, and L. Liao, 2013b: Empirical conversion of vertical profile of reflectivity (VPR) from Ku-band to S-band frequency. J. Geophys. Res. Atmos., 118, 1814-1825, doi:10.1002/jgrd.50138.

Doviak, J. R., and D. S. Zrnić, 1993: Doppler Radar and Weather Observations. Dover, $562 \mathrm{pp}$.

Fabry, F., and I. Zawadzki, 1995: Long-term radar observations of the melting layer of precipitation and their interpretation. J. Atmos. Sci., 52, 838-851.

Houze, R. A., Jr., 2004: Mesoscale convective systems. Rev. Geophys., 42, RG4003, doi:10.1029/2004RG000150.

Howard, B. B., 2007: Advances in applications of the physics of fluids to severe weather systems. Rep. Prog. Phys., 70, 1259, doi:10.1088/0034-4885/70/8/R01.

Iguchi, T., T. Kozu, R. Meneghini, J. Awaka, and K. Okamoto, 2000: Rain-profiling algorithm for the TRMM Precipitation Radar. J. Appl. Meteor., 39, 2038-2052.

—, - J. Kwiatkowski, R. Meneghini, J. Awaka, and K. Okamoto, 2009: Uncertainties in the rain profiling algorithm for the TRMM Precipitation Radar. J. Meteor. Soc. Japan, 87A, 1-30.
Kitchen, M., R. Brown, and A. G. Davies, 1994: Real-time correction of weather radar data for the effects of bright band, range and orographic growth in widespread precipitation. Quart. J. Roy. Meteor. Soc., 120, 1231-1254.

Klazura, G. E., J. M. Thomale, D. S. Kelly, and P. Jendrowski, 1999: A comparison of NEXRAD WSR-88D radar estimates of rain accumulation with gauge measurements for high- and lowreflectivity horizontal gradient precipitation events. J. Atmos. Oceanic Technol., 16, 1842-1850.

Koistinen, J., 1991: Operational correction of radar rainfall errors due to the vertical reflectivity profile. Preprints, 25th Int. Conf. on Radar Meteorology, Paris, France, Amer. Meteor. Soc., 91-94.

Marshall, J. S., W. Hitschfeld, and K. L. S. Gunn, 1955: Advances in radar weather. Advances in Geophysics, Vol. 2, Academic Press, 1-56.

McFarquhar, G. M., M. S. Timlin, R. M. Rauber, B. F. Jewett, J. A. Grim, and D. P. Jorgensen, 2007: Vertical variability of cloud hydrometeors in the stratiform region of mesoscale convective systems and bow echoes. Mon. Wea. Rev., 135, 3405-3428.

Meneghini, R., T. Iguchi, T. Kozu, L. Liao, K. Okamoto, J. A. Jones, and J. Kwiatkowski, 2000: Use of the surface reference technique for path attenuation estimates from the TRMM Precipitation Radar. J. Appl. Meteor., 39, 20532070.

, J. A. Jones, T. Iguchi, K. Okamoto, and J. Kwiatkowski, 2004: A hybrid surface reference technique and its application to the TRMM Precipitation Radar. J. Atmos. Oceanic Technol., 21, $1645-1658$

Qi, Y., and J. Zhang, 2013: Correction of radar QPE errors associated with low and partially observed brightband layers. J. Hydrometeor., in press.

,-- , and P. Zhang, 2013a: A real-time automated convective and stratiform precipitation segregation algorithm in native radar coordinates. Quart. J. Roy. Meteor. Soc., doi:10.1002/ qj.2095, in press.

,,,--- and Q. Cao, 2013b: VPR correction of bright band effects in radar QPEs using dual polarimetric radar observations. J. Geophys. Res. Atmos., 118, 3627-3633, doi:10.1002/ jgrd.50364.

Ryde, J. W., 1947: The attenuation and radar echoes produced at centimeter wavelengths by various meteorological phenomena. Meteorological Factors in Radio Wave Propagation, The Physical Society, 169-188.

Ryzhkov, A., M. Pinsky, A. Pokrovsky, and A. Khain, 2011: Polarimetric radar observation operator for a cloud model with spectral microphysics. J. Appl. Meteor. Climatol., 50, 873-894.

Seo, D. J., C. R. Kondragunta, K. Howard, S. Vasiloff, and J. Zhang, 2005: The National Mosaic and Multisensor QPE (NMQ) Project-Status and plans for a community testbed for high-resolution multisensor quantitative precipitation estimation (QPE) over the United States. Preprints, 19th Conf. on Hydrology, San Diego, CA, Amer. Meteor. Soc., 1.3. [Available online at https://ams.confex.com/ams/pdfpapers/86485.pdf.]

Vasiloff, S. V., and Coauthors, 2007: Improving QPE and very short term QPF: An initiative for a community-wide integrated approach. Bull. Amer. Meteor. Soc., 88, 18991911.

Wexler, R., and D. Atlas, 1956: Factors influencing radar echo intensities in the melting layer. Quart. J. Roy. Meteor. Soc., 82, 349-351. 
Yang, Y., X. Chen, and Y. Qi, 2013: Classification of convective/ stratiform echoes in radar reflectivity observations using a fuzzy logic algorithm, J. Geophys. Res. Atmos., 118, 18961905, doi:10.1002/jgrd.50214.

Zhang, J., and Y. Qi, 2010: A real-time algorithm for the correction of brightband effects in radar-derived QPE. J. Hydrometeor., 11, 1157-1171.

, K. Howard, and J. J. Gourley, 2005: Constructing threedimensional multiple radar reflectivity mosaics: Examples of convective storms and stratiform rain echoes. J. Atmos. Oceanic Technol., 22, 30-42.
_ C. Langston, and K. Howard, 2008: Brightband identification based on vertical profiles of reflectivity from the WSR-88D. J. Atmos. Oceanic Technol., 25, 1859-1872.

_ QPE (NMQ) System: Description, results, and future plans. Bull. Amer. Meteor. Soc., 92, 1321-1338.

—_, Y. Qi, D. Kingsmill, and K. Howard, 2012: Radar-based quantitative precipitation estimation for the cool season in complex terrain: Case studies from the NOAA Hydrometeorology Testbed. J. Hydrometeor., 13, 18361854. 